\title{
Male-Biased Sex Ratios, Female Promiscuity, and Copulatory Mate Guarding in an Aggregating Tropical Bug, Dysdercus bimaculatus
}

\author{
Scott P. Carroll ${ }^{1}$ and Jenella E. Loye ${ }^{1}$ \\ Accepted November 21, 1988; revised January 4, 1989
}

The ecological and social bases of the mating system of the seed-feeding bug, Dysdercus bimaculatus (Hemiptera: Pyrrhocoridae), were studied in the lab and in aggregations at the host tree, Sterculia apetala (Malvales: Malvaceae), in Panama. On theoretical grounds, two factors are predicted to be of importance in determining the evolution of male mating tactics in this species: the operational sex ratio and the probability that undefended females will mate with other males, subjecting the gametes of deserters to sperm competition. Results of a study of a related species suggested that sperm displacement is probably substantial. Adult sex ratios at numerous sites were significantly male biased, and females whose mates were removed remated before oviposition (i.e., sperm utilization). These results predict that a mate defense tactic is likely to be superior to a nondefense tactic. The biological significance of the parameters is supported by observations that captive pairs often remained in copula for several days, until just before oviposition. However, substantial variation in copulation duration was also observed, and possible causes of this variation are considered. Causes of male biased adult sex ratios were investigated by monitoring demographic changes within a single aggregation over 2 months. Both female juvenile and adult mortality rates were greater than male. In addition, dissections of reproductive adults showed that the fight muscles of females, but not males, had histolyzed, so that female reproduction is physiologically limited to a single site. Greater rates of immigration among both mature and young males suggests that an excess of males may also be found in the populations of bugs that subsequently colonize other host plants, so that female scarcity is typical of aggregations in all stages of development. The evolution of sex-lim-

\footnotetext{
${ }^{1}$ Department of Biology, University of Utah, Salt Lake City, Utah 84112.
} 
ited flight muscle histolysis may be explained by greater patchiness of females than males as mating resources, plus a lower energetic benefit/cost ratio of histolysis for males.

KEY WORDS: aggregation; dispersal; Dysdercus bimaculatus; Hemiptera; mate guarding; Panama; Pyrrhocoridae; sex ratio; sexual selection; Sterculia apetala.

\section{INTRODUCTION}

Mate guarding, in which a male defends access to a female's ova from other males, while forfeiting, at least temporarily, the opportunity to search for additional matings, has been reported in several insect orders (Parker, 1970; Thornhill and Alcock, 1983). Two classes of selective factors have probably contributed to this behavioral convergence among insect groups, notably ecological circumstances that either reduce the encounter rates of individual males with females or increase the probability of sperm competition within females. For example, males of many species aggregate for mating at sites where females emerge, feed, or oviposit. Because females may spend substantial periods away from such sites, the sex ratio at the mating site may become male biased, resulting in competition among males for matings. This may result in the evolution of mating tactics such as the territorial defense of sites where females aggregate (in which case more than one female may be defended simultaneously) or, in the extreme, the physical defense of a single female for a period ranging from a few minutes to the entire male life span (sensu Emlen and Oring, 1977; e.g., Thornhill, 1980; Wing, 1985).

Long-term monogamous guarding of a female, as occurs in some stick insects in which the adult sex ratio is male biased (Sivinski 1978), may be favored even in the absence of sperm competition if the average male is likely to encounter few females in his lifetime. However, males of many species may be vulnerable to sperm displacement because females store sperm for some period between insemination and fertilization (which occurs at oviposition) and may mate again before utilizing an initial male's sperm. This circumstance will also favor guarding of the female, over the alternative of searching for multiple matings, if searching precludes a male from guarding (sensu Parker, 1970, 1974; Yamamura, 1986).

Bugs of the genus Dysdercus (cotton stainers) are noted to remain in copula for periods of many hours or days (Ballard and Evans, 1928; Srivastava and Bahadur, 1958; Derr, 1980a). However, no ecological or evolutionary examination of this behavior has been reported. Several factors suggested that prolonged copulation might function as postinsemination mate guarding. First, Dysdercus spp. are noted for occurring in dense reproductive aggregations on their host plants (e.g., Meyers, 1927; Van Doesburg, Jr., 1968; Janzen, 1972; 
Fuseini and Kumar, 1975; Derr, 1980b). High density will increase the encounter rate between the sexes and, thus, the probability that an unguarded female will mate again before oviposition. Second, should females mate multiply, the sperm displacement rate may be great. Harwalker and Rahalkar (1973) reported that in Dysdercus koenigii F., males that mated after a female's first oviposition fertilized about $65 \%$ of eggs in the second clutch $(35 \%$ were fertilized by the first male), and ever increasing proportions went to the second male in the third through the sixth (last) clutches, even though the females were not inseminated again. Third, while adult sex ratios have not been reported for Dysdercus in the wild, there are two reasons to predict that males may outnumber females. First, a sex difference migratory potential could produce male biased sex ratios. Females histolyze their wing muscles upon initiating reproduction, while males do not (Edwards, 1970; Gatehouse and Hall, 1976; Derr, 1980b; Nair and Prabhu, 1985a,b). As a result, the reproductive life span of female Dysdercus can be no greater than the duration of seed availability at the host plant upon which they initiate reproduction (or at other host plants within walking distance). In contrast, males retain the potential to fly among host plants. This difference could lead to a male bias in adult sex ratio, particularly at newly colonized host plants. Second, male Dysdercus generally outlive females in the lab, independent of food shortage (Vridagh, 1941; Dingle, 1966), and malebiased sex ratios in the field could result from longevity differences as well. Such a bias would favor guarding if unguarded females remate quickly, and high density (rapid encounter rates) will particularly favor guarding in aggregations with male biased sex ratios (Yamamura, 1986).

The purpose of this study was to document the reproductive behavior of Dysdercus bimaculatus in the field and in captivity and to determine whether aspects of natural aggregations, particularly the remating intervals of females experimentally separated from their mates, and adult sex ratios could promote the evolution of mate defense by males.

\section{STUDY ANIMAL AND METHODS}

Dysdercus bimaculatus ranges from Venezuela to the extreme southern United States (Van Doesberg, Jr., 1968) and, in Central America, specializes on seeds of the large trees Sterculia apetala (Sterculeaceae), Ceiba pentandra (Malvaceae), Pseudobombax septinatum (Malvaceae), and Bombacopsis quinata (Malvaceae) (Janzen, 1972; Derr, 1980a). These trees mature seeds asynchronously during the tropical dry season (circa December-May), and $D$. bimaculatus flies between the widely spaced host plants (Derr, 1980b). Captive female $D$. bimaculatus (at $27^{\circ} \mathrm{C}$ ) were found to lay an average of six $100 \mathrm{egg}$ clutches at intervals of 5-6 days (Derr, 1980a). 


\section{Studies of Prolonged Copulation and Guarding}

This study was conducted in the Republic of Panama during February, March, and April of 1985. Studies of mating in captive populations were made under natural shaded light and temperature conditions in screen houses at the Smithsonian Tropical Research Institute facility on Barro Colorado Island (BCI). Daytime temperatures averaged $27^{\circ} \mathrm{C}$ (range, $23-30^{\circ} \mathrm{C}$ ). Mating durations and frequencies were measured in groups of adults at $1: 1$ and $2: 1$ male-biased sex ratios (reflective of sex ratios in nature). The two groups were of adults 5-8 days posteclosion, one consisting of 12 males and 12 females and the other of 16 males and 8 females, contained in straight-walled plastic buckets of $40-\mathrm{cm}$ diameter, the walls of which were coated with friction-reducing Fluon AD-1 to prevent escape. These adults were initially isolated by sex, after molting to adulthood from groups of fifth-instar nymphs collected in the field. Each was given a unique pattern of three color dots on the scutellum and pronotum with Tek-Pen glass-marking inks. Water in cotton-stoppered vials and locally collected seeds of $S$. apetala were provided ad libitum. The mating status, the identity of mates, and how gravid the females were all were recorded each day for 14 days (twice per day for the first 3 days, once per day thereafter). Female egg content was ranked on a scale of abdominal expansion of 1-4. " 1 " denoted an abdomen whose shape did not differ from that at eclosion, " 2 " a ventral expansion of the abdomen, " 3 "' a ventral and lateral expansion of the abdomen, and " 4 " a ventral, lateral, and dorsal expansion of the abdomen. Adults that died during the course of the study were replaced with mature virgins from the stocks of adults isolated by sex.

Because females are secretive at oviposition, oviposition was rarely observed directly. The hypothesis that mate changes occur in association with oviposition, when pairs must uncouple, was examined by comparing the frequency of declines in female abdominal expansion (indicative of oviposition), from one observation to the next, for periods in which a female remained with the same male, versus periods in which a female obtained another mate or lost a mate.

Development Time. If males and females differed in development time, a sex ratio bias toward the more rapidly developing sex could result. Development time was measured for bugs that hatched from eggs laid in captivity by females collected in the field. The nymphs were reared in 1-pt plastic freezer containers that had filter-paper bottoms and mesh tops. Seeds and water were provided ad libitum.

Flight Muscle Histolysis. The condition of the flight muscles of 10 mating pairs collected from the Ancon aggregation (below) and of 10 males and 10 females 3 days posteclosion (prereproductive) reared in captivity was examined by dissection and stereomicroscopy. 


\section{Field Studies}

Initial observations of bugs at night suggested that activity was greatly reduced relative to daytime rates. In two nocturnal observations of a total of 33 adult males and 14 adult females under a Sterculia on BCI, viewed with flashlights equipped with low-density red filters, no locomotion was observed; feeding was observed in 4 mated and 1 single female. Subsequent observations were limited to daytime samples (described below), and only these are reported in this paper.

Population Dynamics, Sex Ratios. Field observations were made at a focal aggregation beneath two 20- to 25-m-tall Sterculia apetala trees with contiguous canopies in Ancon Park (Panama City). This aggregation was studied between 1200 and 1800 hr on 12 Feb., 21 Feb., 5 Mar., 12 Mar., 17 Mar., 26 Mar., and 9 Apr. 1985. The ground surface beneath the canopies consisted of short dry grass and bare dirt, providing few places in which the bugs were concealed from view. In this region, where the bugs fed on fallen seeds, the numbers of single males, single females, mating pairs, and teneral adults were counted. (The shiny, pliable exoskeletons of teneral adults persist for 3 days after eclosion in the laboratory. Teneral bugs feed but do not mate or fly.)

Movement and Feeding Frequencies. Instantaneous samples (Altmann 1973) of movement (locomotion on foot) and feeding (presence or absence) were recorded for individual adult males and females, single and mated, between 1400 and $1700 \mathrm{hr}$, during several of the censuses of the focal aggregations.

Age Structure. To measure the age structure of the juvenile population, samples of at least 200 nymphs were collected at random from the ground on 5 Mar., 12 Mar., and 26 Mar., and 50 nymphs were collected on 12 Feb. The mean age class (instar) of sampled nymphs, weighted by the number in each instar, was calculated. First-instar nymphs, which do not feed and remain concealed at the site of hatching, were not included in this calculation. In addition, the number of seed capsules fallen to the ground since the previous sample was recorded.

Time to Remating by Females in Experimentally Separated Mating Pairs. In order to determine whether unguarded females would remate before using at least some of an initial males' sperm (i.e., before an oviposition), 20 mating pairs were separated by gently holding the male with forceps while the female pulled away. These females were then given a unique paint dot on the dorsum and observed continuously until they mated with another male. Ten such observations were made on 21 Feb., and ten on 9 Apr.

Flight Ability as a Function of Sex and Reproductive Condition. Flight abilities of mating and single adults were investigated at Ancon by tossing individuals into the air and recording the presence or absence of flight before they returned to earth. 
Adult Mortality. Adult mortality was examined at Ancon by counting the bodies that accumulated on the ground. The dry conditions during the study period retarded decomposition.

Additional Aggregation Sex Ratios. Counts of single males, single females, and mating pairs were also made in aggregations at six roadside trees along a 27-km transect on Punta Chame peninsula (on the Pacific coast $65 \mathrm{~km}$ west of Panama City) on 15 Feb. and 11 Mar. Bugs were counted in 40-min samples on the ground beneath the trees, on the trunks, and on any pendant seed capsules within reach $(4 \mathrm{~m})$.

\section{RESULTS}

\section{Prolonged Copulation and Mate Guarding}

Individually marked mating pairs in captivity remained in copula for from one to six contiguous daily observations (Fig. 1). Equating each observation of a pair in copula with 1 day's mating duration, the mean $( \pm \mathrm{SD})$ duration for bugs in the $1: 1$ sex ratio group was $2.1 \pm 1.0$ days (range, $1-4$ days), not different from that of bugs in the $2: 1$ sex ratio group $(2.2 \pm 1.4$ days; range, 1-6 days) ( $U=1149.5, P=0.49$, Mann-Whitney $U$ test). The frequency of mating by females was higher, but not significantly so, in the $2: 1$ group than in the $1: 1$ group (87/97 versus $123 / 151$ observations, respectively; $\chi^{2}=3.09$, $P=0.08$ ).

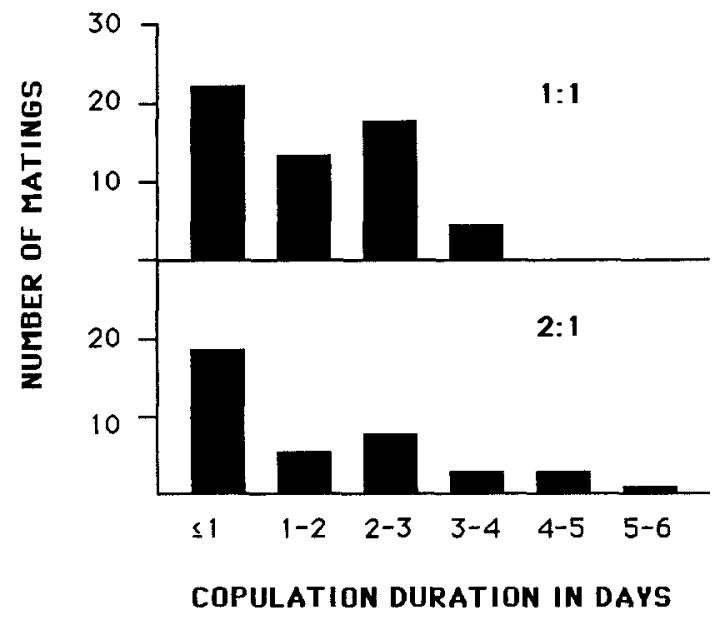

Fig. 1. Copulation durations from daily samples of captive Dysdercus bimaculatus at $1: 1$ and 2:1 male:female sex ratios. 
Pairs were never observed to separate, either in the field or in the laboratory, but must do so for the female to oviposit. Only two ovipositions were observed in the field, in loose, dry dirt beneath organic debris. Neither female was accompanied by a male, suggesting that males do not guard females during oviposition. Oviposition occurred commonly in captive groups but occurred mainly at night, under mats of damp sphagnum, and was never directly observed. Consistent with this, captive females were significantly more likely to increase in egg content during a mating with a particular male than between periods in which they changed mates and were significantly more likely to decrease in egg content (indicating oviposition) between matings than within matings (Table I).

\section{Dynamics of the Ancon Aggregation}

Food Availability. Observations began in the first half of the dry season, when the Sterculia apetala were flowering. A few pods still maturing seeds from the previous season served, as they gradually fell, as the food source for the aggregation at the Ancon site. This aggregation consisted of six species of Dysdercus, with $D$. bimaculatus the most common, followed by $D$. mimus (Say) and D. basialbus (Schmidt). Nymphs of these three species contributed to a juvenile population of several thousand individuals. The seed crop from these two trees was relatively small, and most feeding activity was on the seeds in the 1-30 recently fallen pods under the trees at each sample period (Fig. 1) [trees often produce hundreds or thousands of pods (personal observation; Janzen, 1972; Derr, 1980b)]. The absence of feeding scars on recently fallen pods suggests that few or no bugs were feeding on seeds in the canopy before they fell. Most fallen seeds were exhausted in 1 week or less.

Aggregation Dynamics and Mating Frequency. Adult population size and the proportion of adults mating tended to vary with food availability (Fig. 2). The adult population was smallest in early March when the fewest new fallen pods were present. Increased seed fall in late March was accompanied by the

Table 1. Distribution of Increases and Decreases in Gravidness of Captive Female $D$. bimaculatus, Within and Between Matings

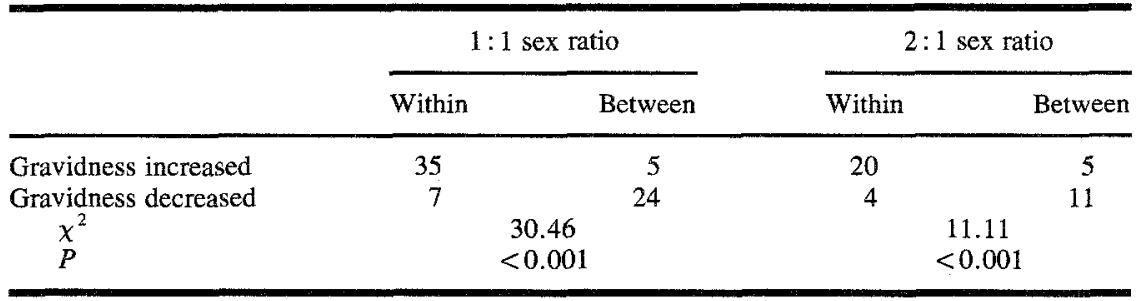




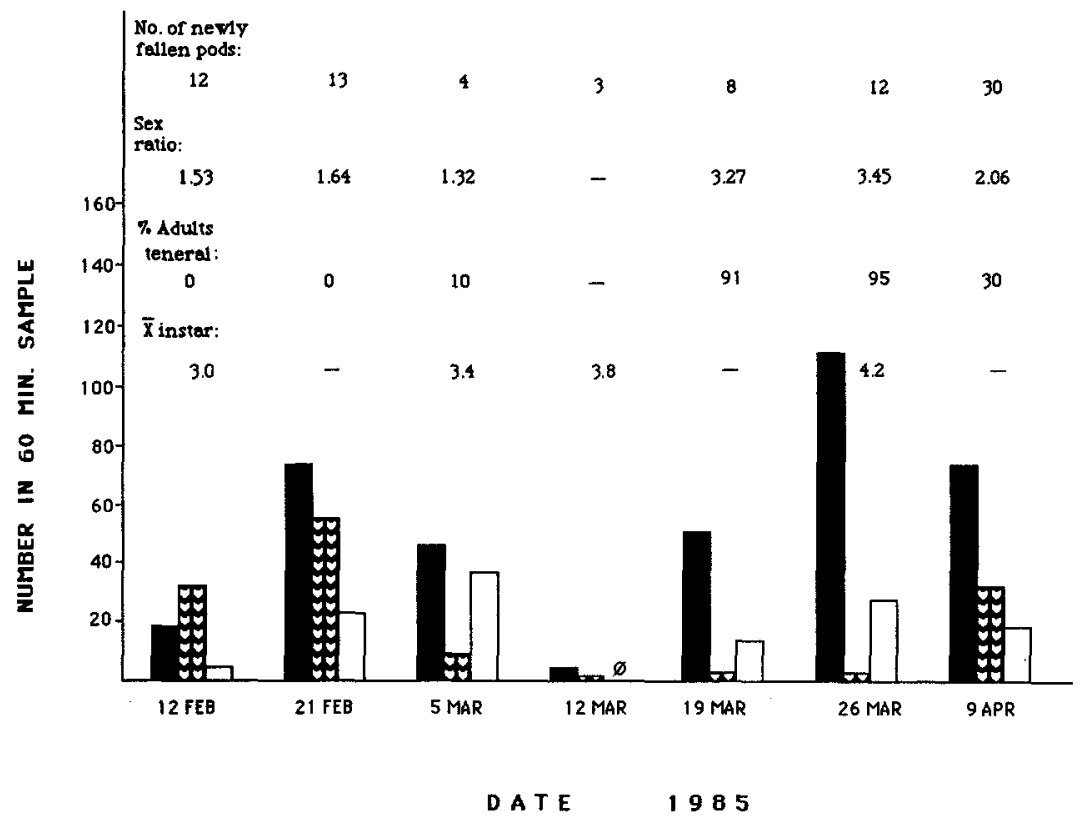

Fig. 2. Adult population composition of Dysdercus bimaculatus on Sterculia apetala at Ancon, Panama. Black bars indicate single males, bars with hearts are mating pairs, and open bars are single females. Data given for each sampling period include the number of seed pods fallen since the previous sample, the ratio of adult males to adult females, the percentage of adults that were teneral (molted to adulthood within 3 days of the sample), and the "mean instar."

molting of large numbers of nymphs to adulthood when $90 \%$ (19 March) and 94\% ( $26 \mathrm{March}$ ) of the sampled adults were teneral. No adults were observed flying in to the aggregation during any sample period.

The mean age (instar) of the nymphs increased throughout the sampling period, from 3.0 on 12 Feb. to 4.2 on 26 Mar. (Fig. 2), suggesting that most oviposition occurred before this study commenced.

The proportion of bugs mating was greater in samples when relatively more new pods were available (Fig. 2) (except on Mar. 26, when almost all of the adults were teneral). The proportion of adults mating was highest on 12 Feb. ( $54 \%$ of males, $88 \%$ of females), 21 Feb. (42\% of males, $70 \%$ of females), and 9 Apr. (29\% of males, $60 \%$ of females). The sample of 9 Apr. showed the adult population to have declined since 26 Mar., implying that many of the new adults were emigrating. However, because by 9 Apr., only $30 \%$ of the adults sampled were teneral, the increased number of mating bugs suggests that some new adults were staying to breed.

Sex Ratio. Adult males outnumbered adult females in all samples (Fig. 2). 
These values include all adults, i.e., both mature and teneral individuals. The mean sex ratio for these six samples was $2.21 \pm 0.92$ males/female. Similar values were found in nine samples at six sites on Punta Chame in February and March (Table II).

Several processes were examined which may explain the male bias. First, female juvenile mortality may have been greater than male. During the course of the observations at Ancon (Fig. 2), a large cohort of nymphs was developing to adulthood. Many of these made the final molt in late March and early April. The sex ratio of these new adults was clearly significantly male biased: 46 males/12 females on 19 Mar., 103 males/27 females on 26 Mar., and 33 males/ 10 females on 9 Apr. The pooled sample of 182 males $/ 49$ females gives a teneral adult sex ratio of 3.7 males per female for this period.

Second, male-biased sex ratio could result simply because males develop more quickly than do females (this effect would be particularly evident in an increasing population). The times from hatch to adulthood of 12 male and 11 female $D$. bimaculatus in captivity were $35.0 \pm 5.3$ and $40.9 \pm 4.6$ days, respectively ( $U=20, P<0.005$, Mann-Whitney $U$ test).

Third, more prereproductive females than males may leave aggregations. Few mature adults were found in the 26 Mar. sample, suggesting that most teneral adults in the 19 Mar. sample had departed. In the 26 Mar. sample, 103 teneral males and 27 teneral females were counted (sex ratio $=3.75: 1$ ). By 9 Apr., 64 mature males and 37 mature females were counted (sex ratio $=1.73: 1$, similar to the February sex ratios when only mature adults were present). These sex ratios are significantly different $\left(\chi^{2}=30.74, P<0.001\right)$, and if the mature adults of 9 Apr. represent a nonimmigrating fraction of the adults maturing at the site, a significantly greater proportion of prereproductive males than prereproductive females left the aggregation.

Table II. Numbers of Male and Female Dysdercus bimaculatus Sampled at Nine Isolated SeedBearing Sterculia apetala Along a 27-km Transect on Punta Chame, Panama, in 1985

\begin{tabular}{|c|c|c|c|c|c|c|c|}
\hline \multirow[b]{2}{*}{ Site } & \multirow[b]{2}{*}{ Date } & \multicolumn{3}{|c|}{ Total } & \multicolumn{3}{|c|}{ Single } \\
\hline & & Males & Females & $\mathrm{M} / \mathrm{F}$ & Males & Females & $\mathrm{M} / \mathrm{F}$ \\
\hline 0 & 15 Feb. & 31 & 14 & 2.40 & 27 & 10 & 2.70 \\
\hline 1 & 15 Feb. & 215 & 102 & 2.12 & 127 & 14 & 9.07 \\
\hline 1 & 11 Mar. & 107 & 72 & 1.49 & 81 & 46 & 1.76 \\
\hline 5 & 11 Mar. & 169 & 128 & 1.32 & 58 & 27 & 1.80 \\
\hline 8 & 15 Feb. & 63 & 34 & 1.85 & 48 & 20 & 2.40 \\
\hline 8 & 11 Mar. & 85 & 54 & 1.57 & 58 & 27 & 2.15 \\
\hline 9 & 15 Feb. & 27 & 14 & 1.93 & 18 & 5 & 3.60 \\
\hline 9 & 11 Mar. & 51 & 25 & 2.04 & 33 & 7 & 4.71 \\
\hline 11 & 11 Mar. & 213 & 118 & $1: 75$ & 137 & 41 & 3.34 \\
\hline
\end{tabular}


Finally, reproductive females may be shorter-lived than reproductive males. Accumulated dead adults were censused on 26 Mar. and 9 Apr., and a total of 26 males and 46 females was found. The ratio of dead males to dead females differs significantly from that expected from the mean ratio of 1.64 mature males per mature female in the samples of live bugs at Ancon $\left(\chi^{2}=21.4, P<\right.$ 0.0001 ).

Time to Remating by Females in Experimentally Separated Mating Pairs. All 20 females separated from their mates remated in less than 30 min. The mean remating time was $9 \min 40 \mathrm{~s} \pm 3 \min 33 \mathrm{~s}$ (range, $14 \mathrm{~s}-25 \min 2 \mathrm{~s}$ ). Four females resisted initial mating attempts but mated with other males soon thereafter. Times to remating were similar on each of the two sampling dates.

Frequencies of Movement and Feeding. Instantaneous samples of movement (locomotion on foot) and feeding were recorded for 204 single males, 56 single females, and 189 mating pairs. Sex and mating status significantly affected both movement frequency $\left(\chi^{2}=122.10, P<0.001\right)$ and feeding frequency $\left(\chi^{2}=32.51, P<0.001\right)$. In comparisons between pairs of adult classes, single males moved significantly more frequently than other adults, single females moved more than mating females, and mating females fed significantly more frequently than other adults (Table III). Feeding was especially infrequent in mating males.

Flight Muscle Histolysis. Flight muscle fibers occurred in either of two conditions, tight bundles of firm fibers in clear hemolymph or smaller numbers

Table III. Movement and Feeding Frequencies of Single Males, Single Females, and Mating Pairs of Dysdercus bimaculatus in the Ancon Aggregation ${ }^{a}$

\begin{tabular}{|c|c|c|c|c|c|}
\hline \multirow[b]{2}{*}{$\begin{array}{l}\text { Feeding } \\
\text { frequency }\end{array}$} & & \multicolumn{4}{|c|}{ Movement frequency } \\
\hline & & $\begin{array}{l}\text { Single } \\
\text { males }\end{array}$ & $\begin{array}{c}\text { Mating } \\
\text { males }\end{array}$ & $\begin{array}{l}\text { Single } \\
\text { females }\end{array}$ & $\begin{array}{l}\text { Mating } \\
\text { females }\end{array}$ \\
\hline & & $138 / 194(71.1 \%)$ & - & $23 / 53(43.3 \%)$ & $20 / 160(12.5 \%)$ \\
\hline $\begin{array}{l}\text { Single } \\
\text { males }\end{array}$ & $10 / 204(4.9 \%)$ & & - & $\chi^{2}=\underset{* *}{14.11}$ & $x^{2}=\underbrace{121}_{* *}$ \\
\hline $\begin{array}{l}\text { Mating } \\
\text { males }\end{array}$ & $2 / 189(1.1 \%)$ & $\begin{array}{c}x^{2}=4.89 \\
*\end{array}$ & & - & - \\
\hline $\begin{array}{l}\text { Single } \\
\text { females }\end{array}$ & $3 / 56(5.4 \%)$ & $\begin{array}{c}\chi^{2}=0.02 \\
\text { NS }\end{array}$ & $\begin{array}{c}x^{2}=3.99 \\
*\end{array}$ & & $x^{2}=23.59$ \\
\hline $\begin{array}{l}\text { Mating } \\
\text { females }\end{array}$ & $29 / 189(17.2 \%)$ & $\chi^{2}=\underbrace{11.97}_{* *}$ & $\chi^{2}=25.62$ & $x^{2}=3.79$ & \\
\hline
\end{tabular}

${ }^{a}$ Feeding individuals were excluded from calculations of movement frequency. Data for each behavior are listed under the headings for each column or after the headings for each row; the values are compared within each triangular portion of the table. No values are listed for movement by mated males because their locomotion, walking backward, depends on whether their mates are walking. $(*) P \leq 0.05$; $\left.{ }^{*} *\right) P<0.001$. 
of thin, flaccid, unbound fibers in cloudy hemolymph. The latter condition, indicating histolysis, was observed only in mating females (9 of 10). All 10 prereproductive females had unhistolyzed fibers, as did all of the 10 mating and 10 single males.

Of 20 mating females separated from their partners and thrown into the air at the Ancon site, none flew, but 13 of their 20 male partners did fly. In contrast, 12 of 20 single, nonteneral, nongravid females flew for short distances, as did 14 of 20 nonteneral single males.

\section{DISCUSSION}

Three principal variables were considered important in determining the evolution of male mating behavior in this insect: the probability of encountering single females (a function of operational sex ratio), the probability that undefended females will remate before using a previous male's sperm, and the sperm displacement rate should a female mate with more than one male. Male-biased sex ratios, rapid remating by females, and a probable high sperm displacement rate (as reported for a related species) combine to predict that some form of mate defense will be favored over postinsemination abandonment and resumption of mate searching. To the extent that these variables may be considered independent of male behavior in this species, the concordance between the predicted tactic and the observed prolonged postinsemination copulation in $D$. bimaculatus indicates that we have correctly identified important variables affecting the evolution of its mating system.

However, substantial and interesting variation was observed in mating durations. Factors contributing to this variation, plus alternative hypotheses for the evolution of prolonged copulation, and the strategic dimorphism in male and female life histories, and discussed below.

\section{Prolonged Copulation}

Mating pairs of Dysdercus bimaculatus commonly remained in copula for several days, but most copulations were much briefer than the 6-day interval between ovipositions for this species in captivity described by Derr (1980a). The coincidence between declines in female abdominal expansion (indicating oviposition) and partner changes suggests that the interval between ovipositions was much briefer in the present study, averaging 2-3 days.

The variation in copulation duration may result from differences in oviposition intervals or in female resistance to prolonged mating or from differences in male mating decisions or, possibly, physical displacement by other males. Displacement was not observed, however, and may usually be prevented by the enlarged, hook-like parameres of the male genitalia. 
Experimentally exposed females remated in an average of about $10 \mathrm{~min}$. Because the average oviposition interval, and thus the interval of utilization of some of the stored sperm, is at least 2-3 days, it is very likely that the gametes of a male that releases a female after inseminating her will be exposed to competition with those of other males in the aggregation. If sperm displacement rates in $D$. bimaculatus are similar to those of $D$. koenigii, then remating by an unguarded female would represent a substantial cost to male reproductive success that could be offset only by rapid multiple mating in an aggregation with a less strong male bias in sex ratio (sensu Yamamura, 1986).

However, such sex ratios are not common in this species. Assuming that equal numbers of male and female eggs are laid and hatch (biasing of the primary sex ratio is not known for Hemiptera), more males than females survived to maturity in aggregations. Even though female development time is greater than that of males, the phenology of the aggregation in Fig. 2 shows that this difference is not great enough to explain the consistent male biasing among the teneral adults: the male bias observed on 19 Mar. persisted in the sample over the next 3 weeks and was not balanced by an excess of later-developing females in April as the number of teneral bugs decreased.

The prevalence of males in all censuses contrasted with the preponderance of females among the dead adults counted near the end of the study, by which time few live, nonteneral adults remained. These results suggest not only that males were living longer than females, but also that they were flying away, with the possibility of colonizing other host trees.

Biasing of the operational sex ratio toward males reduces the average reproductive success of males to a value below the egg output of the average female. In this circumstance, any male that defends his sperm from displacement by other males is likely to fertilize more eggs than males that do not guard, and the guarding trait should quickly spread over generations. As guarding spreads it will further increase the ratio of mature single males to mature single females in aggregations, and the probability of finding additional mates during the guarding period will progressively decline. The observed high movement frequencies and low feeding frequencies of single males may reflect selection for behaviors that increase encounter rates with rare single females. Active males mounted most other adults and late-instar nymphs as they were encountered.

No significant differences were found in the copulation durations of bugs at a $2: 1 \mathrm{male} / \mathrm{female}$ ratio versus a $1: 1$ ratio, although durations of 4-6 days occurred only in the male-biased group. Brief copulations ( 1 day or less) were the most common, but it is not clear what proportion of these terminated with ovipositions. The apparent lack of response by males to increased competition for mates could result either from the fact that the intensity of competition in nature is rather invariably great, favoring guarding under all normal circumstances, or from the fact that guarding is behaviorally constrained to continue 
until oviposition, and female oviposition interval is unaffected by sex ratio. Because males must disengage for their mates to oviposit, and apparently do not guard during oviposition, they may have little option for remating with the same female after oviposition. In addition, if male-male mating displacement does occur on occasion, it would be expected to have been more frequent in the $2: 1$ group, perhaps explaining the greater frequency of brief copulations in that group.

Prolonged copulation could have functions other than mate guarding. It is unlikely, however, that sperm transfer or the transfer of any ejaculatory nutrients takes several days. Walker (1980) suggested that mated pairs (females in particular) might be less susceptible to predation than single individuals, which Sivinski (1980) documented for a stick insect, and McLain (1980) associated prolonged copulation with a decrease in parasitism. However, predation on Dysdercus is seldom observed (e.g., Meyers, 1927; Van Doesburg, Jr., 1968; this study), although infrequent parasitism by tachinid and pipunculid flies did occur in this study.

Male biased sex ratios appear to be a common element in insect species that exhibit mate guarding. Prolonged copulation occurs in a number of hemipteran species (Sweet, 1964), including species that exhibit a great range of sperm competition patterns (e.g., McLain, 1980; Sillén-Tulberg, 1981). Whether male-biased sex ratios are typical of mate guarding hemiptera cannot be generalized because too few studies have reported sex ratios in the field. Other Dysdercus species in Panama and Florida also have more males than females in reproductive aggregations and prolonged copulation (Carroll unpublished), and a similar association of male-biased sex ratios and postinsemination mate guarding is found in temperate populations of the aggregating bug Jadera haematoloma (Carroll, 1988). Similarly, in the short-lived bibionid "lovebug" (Diptera), copulation is for life (females oviposit once), and operational sex ratios in the mating swarms are extremely male biased because males emerge before females and cluster at the emergence sites (Thornhill, 1980). Sivinski $(1978,1983)$ also found a relation between sex ratio and prolonged copulation among phasmodid walking sticks.

\section{Flight Muscle Histolysis and Contrasting Adult Life Histories}

Histolysis of the flight muscles observed in reproductive females confirms the results of Derr (1980b), and the aerial tossing experiments demonstrated that such females do not fly. Such histolysis has been observed in all species of Dysdercus examined to date (see Nair and Prabhu, 1985a), so it is probably a primitive character in this genus. By histolyzing their flight muscles, females lose the capacity to exploit multiple host plants, but this cost is apparently offset by increased egg production (Nair and Prabhu, 1985b) and possibly a low prob- 
ability of finding additional hosts. Reproduction has not been observed away from host plants (this study; Janzen, 1983, p. 627), and thus the distribution of reproductive females shou!d be very similar to that of the seed crops. But females are not present at all trees bearing seeds (Derr, 1980a), so that females are actually more patchily distributed than are seeds, and therefore males may have to sample more trees on average to find females than must females to find seeds. By not histolyzing their flight muscles upon feeding, males retain the option to feed at seed-bearing trees devoid of females before flying to other sites. Moreover, males at sites with females might immigrate if extremely male biased sex ratios prevent them from obtaining mates. It should be noted that in at least some species of Dysdercus, the histolysis of wing muscles by females depends on mating as well as feeding (Nair and Prabhu, 1985a).

In addition, the benefits of redirected resources (via histolysis) would probably be lesser, and the benefits of retained mobility greater, for males than for females. For example, even if histolysis of the wing muscles provided single males with additional energy for mate searching on foot within aggregations, in the present study they were observed to be active in more than $70 \%$ of observations, while feeding less than a third as frequently as reproductive females. Thus they do not seem to be energetically limited in particular, and the energetic cost of egg production must be much greater than that of mate searching by males. Both mate searching and egg production rates should have been pushed in evolutionary time toward some maximum, the former by sexual selection (Darwin, 1874) and the latter by natural selection for early exploitation of a short-lived, limited resource (sensu MacArthur and Wilson, 1967). Only in females, however, has the relevant trait been pushed to semelparity (sensu Kirkendall and Stenseth, 1985). In addition to the greater expense of egg production, females are less morphologically streamlined than males and may be energetically inferior as migrators. Furthermore, some male Dysdercus can persist for long periods on sucrose solutions, while females cannot (Dingle and Arora, 1973), and this gives males the potential for surviving periods between host seed crops by feeding on flower nectar or photosynthate. [Dysdercus are noted for feeding (but not reproducing) on flower nectar (Janzen, 1983, p. 627).] Whether this sex difference played a causal role in the sexual divergence in life histories or is secondarily derived is unknown.

In summary, sexually active male Dysdercus bimaculatus live in an environment in which females are usually rare as reproductive resources, both within and among patches. Because females mate promiscuously and sperm displacement is probably substantial, the excess of males within aggregations suggests analytically that defense of an inseminated female will be favored over abandonment and resumed searching. Paired males commonly copulated with their mates for up to several days, resisting displacement attempts by other males and departing just before oviposition. Single males searched very actively within 
aggregations but, in contrast to females, retained the ability to fly between seedbearing host plants. A population in which old males greatly outnumber females probably accumulates during the breeding season, with new seed crops colonized principally by males, such that males are subject to intense intrasexual competition during all phases of local and regional population cycles.

\section{ACKNOWLEDGMENTS}

This study was brought to life by a fellowship from the Smithsonian Tropical Research Institute. Logistic support in Panama was arranged by Georgina de Alba and Gloria Maggiori. The suggestions of Joe Wright, Henk Wolda, and Annette Aillelo contributed greatly to the success of the study while in progress. Additional help came from Mitch Aide, Monica Geber, Don Feener, Jeff Klahn, Kevin Hogan, Steve Hubbel, and especially Seiji Tanaka. We also thank Eric Charnov, Lissy Coley, and Mark McGinley for discussing this work with us. The comments of John Endler, Carl Schaefer, and especially a maddeningly critical reviewer (alas, anonymous) added a lot to the version you are about to read.

\section{REFERENCES}

Altmann, J. (1973). Observational study of behavior: Sampling methods. Behavior 49: 309-317. Ballard, E., and Evans, M. G. (1928). Dysdercus sidae, Mont., in Queensland. Bull. Entomol. Res. 18: $405-432$.

Carroll, S. P. (1988). Contrasts in the reproductive ecology of temperate and tropical populations of Jadera haematoloma (Hemiptera: Rhopalidae), a mate-guarding insect. Ann. Ent. Soc. Am.

Darwin, C. (1874). The Descent of Man, and Selection in Relation to Sex, 2nd ed., A. L. Burt, New York.

Derr, J. A. (1980a). The nature of variation in life history characters of Dysdercus bimaculatus (Heteroptera: Pyrrhocoridae), a colonizing species. Evolution 34: 548-557.

Derr, J. A. (1980b). Coevolution of the life history of a tropical seed-feeding insect and its food plants. Ecology 61: 881-892.

Dingle, H. (1966). The effect of population density on mortality and sex ratio in the milkweed bug, Oncopeltus, and the cotton stainer, Dysdercus (Heteroptera). Am. Nat. 100: 465-470.

Dingle, H., and Arora, G. (1973). Experimental studies of migration in bugs of the genus Dysdercus. Oecologia 12: 119-140.

Edwards, F. J. (1970). Endocrine control of flight muscle histolysis in Dysdercus intermedius. $J$. Insect Physiol. 16: 2027-2031.

Fuseini, B. A., and Kumar, R. (1975). Ecology of cotton stainers (Heteroptera: Pyrrhocoridae) in southern Ghana. Biol. J. Lirn. Soc. 7: 113-146.

Gatehouse, A. G., and Hall, M. J. R. (1976). The effect of isolation on flight and the pre-oviposition period in unmated Dysdercus superstitiosus. Physiol. Entomol. 1: 15-19.

Harwalkar, M. R., and Rahalkar, G. W. (1973). Sperm utilization in the female red cotton bug. J. Econ. Entomol. 66: 805-806.

Janzen, D. H. (1972). Escape in space by Sterculia apetala from the bug Dysdercus fasciatus in a Costa Rican deciduous forest. Ecology 53: 350-361.

Janzen, D. H. (1983). Costa Rican Natural History, University of Chicago Press, Chicago. 
Kirkendall, L. R., and Stenseth, N. C. (1985). On defining "breeding once." Am. Nat. 125: 189204.

MacArthur, R. H., and Wilson, E. O. (1967). The Theory of Island Biogeography, Princeton University Press, Princeton, N.J.

McLain, D. K. (1980). Female choice and the adaptive significance of prolonged copulation in Nezara viridula (Hemiptera: Pentatomidae). Psyche 87: 325-336.

Meyers, J. G. (1927). Ethological observations of some Pyrrhocoridae of Cuba. Ann. Entomol. Soc. Am. 20: 279-300.

Nair, C. R. M., and Prabhu, V. K. K. (1985a). The role of feeding, mating and ovariectomy on the degeneration of indirect flight muscles of Dysdercus cingulatus (Hemiptera: Pyrrhocoridae). J. Insect Physiol. 31: 35-39.

Nair, C. R. M., and Prabhu, V. K. K. (1985b). Entry of protein from degenerating flight muscles into oocytes in Dysdercus cingulatus (Heteroptera: Pyrrhocoridae). J. Insect Physiol. 31: 383388.

Parker, G. A. (1970). Sperm competition and its evolutionary consequences in the insects. Biol. Rev. Cambridge Philos. Soc. 45: 525-568.

Parker, G. A. (1974). Courtship persistence and female-guarding as male time investment strategies. Behaviour 48: 157-184.

Sillén-Tullberg, B. (1981). Prolonged copulation: A male "post-copulatory" strategy in a promiscuous species, Lygeaus equestris (Heteroptera: Lygaeidae), Behav. Ecol. Sociobiol. 9: 283289.

Sivinski, J. (1978). Intrasexual aggression in stick insects, Diapheromera veliei and D. covilleae, and sexual dimorphism in the Phasmatodea. Psyche 85: 395-406.

Sivinski, J. (1980). The effects of mating on predation in the stick insect Diapheromera veliei Walsh Phasmatodea: Herteronemiidae). Ann. Entomol. Soc. Am. 73: 553-556.

Sivinski, J. (1983). Predation and sperm competition in the evolution of coupling durations, particularly in the stick insect Diapheromera veliei. In Gwynne, D. T., and Morris, G. K. (eds.), Orthopteran Mating Systems: Sexual Competition in a Diverse Group of Insects, Westview Press, Boulder, Colo., pp. 147-162.

Srivastava, U. S., and Bahadur, J. (1958). Observations on the life history of the red cotton bug, Dysdercus cingulatus (Hemiptera: Pyrrhocoridae). Ind. J. Entomol. 20: 228-234.

Sweet, M. H. (1964). The biology and ecology of the Rhyparochrominae of New England (Heteroptera, Lygaeidae). Part II. Entomol. Am. 43: 1-124.

Thornhill, R. (1980). Sexual selection within mating swarms of the lovebug Plecia nearctica (Diptera: Bibionidae). Anim. Behav. 28: 405-412.

Thomhill, R., and Alcock, J. (1983). The Evolution of Insect Mating Systems, Harvard Press, Cambridge Mass.

Van Doesburg, P. H., Jr. (1968). A revision of the new world species of Dysdercus Guerin Meneville (Heteroptera, Pyrrhocoridae). Zool. Verhandel. 97: 1-215.

Vrydagh, J. M. (1941). Etude sur la biologie de Dysdercus superstitiosus F. (Hemiptera). Publications de L'Institute National pour L'Etude Agronomie du Congo Belge, Serie Scientifique, No. 24.

Walker, W. F. (1980). Sperm utilization strategies of nonsocial insects. Am. Nat. 115: 780-799.

Wing, S. R. (1985). Prolonged copulation in Photinus macdermottii with comparative notes on Photinus collustrans (Coleoptera: Lampyridae). Fla. Entomol. 68: 627-634.

Yamamura, N. (1986). An evolutionarily stable strategy (ESS) model of postcopulatory guarding in insects. Theor. Pop. Biol. 29: 438-455. 